\title{
LXXXII. Analysis of the $\gamma$ rays of the thorium and actinium products
}

\section{Prof. E. Rutherford F.R.S. \& H. Richardson M.Sc.}

To cite this article: Prof. E. Rutherford F.R.S. \& H. Richardson M.Sc. (1913) LXXXII. Analysis of the $\gamma$ rays of the thorium and actinium products , Philosophical Magazine Series 6, 26:156, 937-948, DOI: $10.1080 / 14786441308635041$

To link to this article: http://dx.doi.org/10.1080/14786441308635041

$$
\text { 曲 Published online: } 08 \text { Apr } 2009 .
$$

\section{Submit your article to this journal $\sqsubset$}

Џ Article views: 6

Q View related articles $\longleftarrow$

Citing articles: 4 View citing articles $\square$ 


\title{
PHILOSOPHICAL MAGAZINE
}

\author{
$A N D$ \\ JOURNAL OE SCIENCE.
}

[SIXTH SERIES.]

$D E C E M B E R 1913$.

LXXXII. Analysis of the $\gamma$ Rays of the Thorium and Actinium Products. By Prof. E. Rothertoro, F.R.S., and H. Richardoson, M.Sc., Beyer Fellow, University of Manchester*.

[Plate XIX.]

T $N$ previous papers $\dagger$ we have analysed the $\gamma$ radiations 1 emitted by the radium products radium $B$, radium $C$, radium $D$, and radium $E$ into a number of groups of different penetrating powers. An examination of the thorium products, viz., mesothorium 2 , thorium $\mathrm{B}$, thorium $\mathrm{C}$, thorium $D$, and of the actinium products has been undertaken by a similar method, and results of the same general character as in the case of radium have been obtained. The $\gamma$ rays of these substances have been found to consist of distinct groups of rays absorbed exponentially by aluminium and differing widely in their absorption by matter.

As the apparatus and methods employed were the same as those previously used in the investigation of the rays from radium $D$ and radium $\mathbf{E}$, and described in a former paper, it is not necessary to discuss them further here.

Preliminary investigations of the $\gamma$ rays from the thorium products were made by using the active deposit of thorium, obtained by exposure of a negatively charged wire to the emanation from a preparation of mesothorium. The effect obtained was, however, too small for accurate measurement.

* Communicated by the Authors.

$\dagger$ Rutherford \& Richardson, Phil. Mag. xxv. p. 722 (1913), and xxri, p. 324 (1913).

Phil. Mag. S. 6. Vol. 26. No. 156. Dec. 1913. 3 S 


\section{Prof. Rutherford and Mr. Richardson : Analysis of}

To overcome this difficulty, the various active products were separated from a preparation of mesothorium, which had a $\gamma$-ray activity equal to about 2.5 milligrams of radium. Since mesothorium always contains some radium, which is inseparable from it, it was necessary to take precautions that none of the $\gamma$-ray products of the latter should interfere in the measurements.

The mesothorium was dissolved in a very small quantity of dilute $\mathrm{HCl}$ and the solution made up to 0.5 c.c. This solution was heated on a water-bath for six hours, in order to drive off any radium emanation formed in the interval. During that time any radium $B$ or radium $C$ present practically disappeared. A nickel wire $3 \mathrm{~mm}$. in diameter was then rotated in the solution for about 30 minutes, in order to collect the thorium $\mathrm{C}$ upon it. The nickel wire was found to be sufficiently active to show a strong $\gamma$-ray activity in the electroscope, and the purity of the deposit of thorium $C$ was confirmed by examining its rate of decay. The $\gamma$-ray effect due to the nickel wire in this case arose not from the thorium $\mathrm{C}$, which is an $\alpha$-ray product, but from the thorium D.

By suitable chemical operations the mesothorium was separated from the radiothorium. A few details of the chemical methods employed will be given, and we desire to express our thanks to Dr. Russell and Mr. Chadwick for kindly undertaking the work of chemical separation.

To the acid solution of mesothorium a few milligrams of aluminium chloride were added. Pure ammonia gas was then passed into this solution and aluminium hydroxide was precipitated. With this came down also the products mesothorium 2 , radiothorium, thorium $\mathrm{B}$, thorium $\mathrm{C}$, thorium $\mathrm{D}$, and any trace of radium $B$ and radium $C$ that might be present. This precipitate was filtered off and re-dissolved in a small quantity of dilute hydrochloric acid. 10 milligrams of load chloride were then aldded, and $\mathrm{H}_{2} \mathrm{~S}$ was passed through the solution. The precipitate of lead sulphide was filtered off and carried with it the radium $B$, rarlium $C$, thorium $B$, thorium $C$, and thorium $D$. If any radium $B$ or radium $C$ were present, these would decay in the course of a few hours, and the source then consisted of thorium $(B+C+D)$ in equilibrium. Since the radiation from thorium $(C+D)$ was determined in the case of the deposit on the nickel wire, the $\gamma$ radiation from thorium $B$ could be deduced by a comparison of the absorption curves in the two cases.

The filtrate was evaporated to dryness and the $\mathrm{H}_{2} \mathrm{~S}$ 
the $\gamma$ Rays of the Thorium and Actinium Products. 939

expelled. The residue was obtained on a watch-glass and consisted of a thin layer of solid matter. This residue contained all the radiothorium and mesothorium 2. Since radiothorium itself does not emit $\gamma$ rays, the examination of this source immediately after its preparation gave the $\gamma$ rays belonging to mesothorium 2. The latter decays to half value in 6.2 hours, and has practically disappeared in the course of two days. In the meantime the radiothorium had produced thorium $\mathrm{X}$ and its subsequent products, viz. thorium emanation and the active deposit, and this source was used to test again the $\gamma$ radiation from thorium $(B+C+D)$. We obtained no definite evidence that thorium $\mathrm{X}$ emits a quantity of $\gamma$ rays which could be detected in our experiments *.

\section{Analysis of the $\gamma$ rays from Thorium $(\mathrm{C}+\mathrm{D})$.}

The $\gamma$ radiation was examined in the electroscope containing methyl iodide, using, as before, a strong magnetic field to remove the $\beta$ rays. The source used in these experiments consisted of the deposit of thorium $(C+D)$ on the nickel wire mentioned above. The absorption curve showed that two types of radiation were present. About 80 per cent. of the total radiation consisted of a very hard type, which was exponentially absorbed in aluminium and had an absorption coefficient in that substance of $\mu=0.096(\mathrm{~cm} .)^{-1}$. The other radiation present was much less penetrating and was completely stopped by $2 \mathrm{~mm}$. of aluminium. This soft radiation, however, was not absorbed exponentially by aluminium, and would thus appear to be complex in character. The general evidence indicates that th's soft radiation is not emitted by thorium $\mathrm{C}$ or thorium $\mathrm{D}$, but is excited in the nickel by the $\alpha$ or $\beta$ rays. It will be remembered that a radiation of almost identical type was found when radium $C$ was deposited on nickel $f$. It is intended to make a more detailed examination as to whether radiations of this kind are to be attributed to the excitation of one or more types of characteristic radiation by the

* L. Meitner and Hahn (Phys. Zeit. xiv. p. 873, 1913) have recently examined the products thorium $\mathrm{X}$ and thorium $\mathrm{C}$ for $\gamma$ rays. Both of these products have been found to emit $\gamma$ rays in small quantity. The presence of a small amount of $\gamma$ radiation from these substances would. however, have no appreciable effect on the absorption curves obtained by the methods used in our experiments.

$\dagger$ Rutherford \& Richardson, Phil. Mag. xxv. p. 730 (1913). 
$\alpha$ or $\beta$ rays in the material on which the active matter is deposited.

Since thorium $\mathrm{C}$ does not emit any appreciable $\gamma$ radiation, the results of these experiments thus indicate that thorium D emits only one penetrating type. This conclusion was confirmed by examining the $\gamma$ radiation from pure thorium D obtained by recoil on an aluminium plate. Although the effects were too small and the period of transformation too short for accurate measurements, the results clearly indicated that no appreciable amount of soft radiation was present under those conditions.

\section{Analysis of the rays from Thorium $(\mathrm{B}+\mathrm{C}+\mathrm{D})$.}

In order to determine the penetrating power of the rays given out by thorium $B$, it was necessary to use sources containing the active deposit in equilibrium. We have seen above that two sources were prepared for this purpose. When the radiothorium source was employed, the preparation was contained in a watch-glass and covered with goldbeater's skin to prevent the escape of the emanation. The absorption curve, in aluminium, was determined up to a thicliness of $11 \mathrm{~cm}$. The curves obtained are shown in figs. $1 \& 2$ (Pl. XIX.). These curves were analysed by the method described in previous papers*. It will be seen that the curves can be separated into four exponential types corresponding to groups of rays of penetrating powers $\mu=160$, $\mu=32, \mu=0 \cdot 36$, and $\mu=0 \cdot 096$. The last group is of course that due to thorium $\mathrm{D}$, and the remaining three are given out by thorium $B$.

Fig. 1 shows the analysis of the soft types of radiation. The logarithm curve for the second type of radiation $\mu=32$ is shown in the figure. The points lie on a straight line showing that this radiation is absorbed exponentially. Fig. 2 brings out in a similar way the exponential absorption of the penetrating type of radiation $\mu=0 \cdot 09 \hat{b}$, and also the relative effect in the experiments due to the penetrating radiation from thorium $\mathrm{B}$, viz. $\mu=0 \cdot 36$. This latter radiation probably corresponds to that described by Marsden and Wilson $†$ and by Hahn and Meitner $\ddagger$, and noted in papers recently published.

* Rutherford \& Richardson, Phil. Mag. xxv. p. 722 (1913).

t Marsden \& Wilson, Phil. Mag. xxvi. p. 354 (1913).

+ Heitner \& Uahn, Phys. Zeit. xiv, p. 873 (1913). 
Analysis of the $y$ rays from Mesothorium 2.

The mesothorium 2, prepared as described, was used for this experiment. The absorption curves obtained are shown in figs. 3 and 4. Analysis shows that the rays consist of two types, for which $\mu=26$ and $\mu=0.116$ respectively. Fig. 3 shows the method of analysis of the radiation $\mu=26$ and its exponential absorption by aluminium. The logarithm curve in fig. 4 shows the absorption for the penetrating radiation $\mu=0 \cdot 116$.

\section{Analysis of the $\gamma$ rays from Actinium $(\mathrm{B}+\mathrm{C}+\mathrm{D})$.}

The $\gamma$ rays emitted by the actinium products were examined by the same method as that adopted in the case of thorium. Owing to the short periods of actinium $\mathrm{C}(2 \cdot 1 \mathrm{~min}$.) and of actinium $D(4.71 \mathrm{~min}$.) it was impossible to complete the examination of the separate products with the small amount of material at our disposal *.

An actinium preparation was dissolved in hydrochloric acid, and the actinium $\mathrm{X}$ was separated by the ammonia method. In this manner the actinium $X$ was obtained on a watch-glass mixed with a thin layer of material. The preparation was covered with goldbeater's skin as in the case of the radiothorium preparation in order to prevent the escape of the emanation. Shortly after the separation the actinium $\mathrm{X}$ is in equilibrium with its later products actinium $(\mathrm{B}+\mathrm{C}+\mathrm{D})$, and the whole then decays with the comparatively long period of actinium $\mathrm{X}(10 \cdot 2$ days $)$. The $\gamma$ rays in this preparation arise from the active deposit, viz. actinium $(\mathrm{B}+\mathrm{C}+\mathrm{D})$.

The absorption curve in aluminium of this preparation was obtained up to a thickness of $9 \mathrm{~cm}$. Beyond $6 \mathrm{~cm}$. the absorption is exponential with an absorption coefficient $\mu=0 \cdot 198$. The curves obtained are shown in figs. 5 and 6 . Analysis as in previous cases shows that the curves can be separated into exponentials with absorption coefficients $\mu=120, \mu=31, \mu=0 \cdot 46$, and $\mu=0.198$ respectively. Fig. 5 shows the analysis of the softer portions of the radiation, and fig. 6 the separation of the two more penetrating groups. From analogy with the thorium series, there appears to be little doubt that the radiations $\mu=120, \mu=31$, and $\mu=0.46$ belong to actinium $\mathrm{B}$, and that for which $\mu=0.198$ to actinium $\mathrm{D}$.

* The actinium preparation used in these experiments was separated from radioactive residues (see Boltwood, Proc. Roy. Soc. A. Ixxxv. 1911, p. 77) loaned to one of us by the Royal Society. 


\section{Analysis of the $\gamma$ rays from Radioactinium.}

Dr. Russell and Mr. Chadwick recently examined in this Laboratory the $\gamma$ rays from radioactinium, which they found to be far greater in intensity than could be ascribed to excitation by $\alpha$ rays. An approximate analysis was made by them of the types of radiation present. In the course of our later experiments with actinium, the emission of an intense $\gamma$ radiation from radioactinium was evident. The actinium $\mathbf{X}$ was successively separated from the radioactinium preparation, and after the second operation it was found that the $\gamma$ radiation from the precipitate, viz. actinium and radioactinium, reached a definite minimum of activity. Measured in the ordinary electroscope, the $\gamma$-ray effect of the actinium and radioactinium was about 25 per cent. of the activity of the actinium in equilibrinm with all its products. The actinium and radioactinium precipitate formed a comparatively thick deposit of several grams (about 10 grms.) in weight. Notwithstanding this comparatively thick layer, the presence of a considerable amount of soft radiation was evident. Analysis showed that the radiation from this material, which is to be ascribed to radioactinium, consists of two distinct types for which $\mu=25$ and $\mu=\cdot 190$. The absorption curves obtained are shown in figs. 7 and 8 . The $\gamma$-ray effect due to the more penetrating type was less than 2 divs. per min. under the experimental conditions, and it was consequently difficult to determine its absorption coefficient with as great an accuracy as was desired. An examination of the rise curve of the actinium and radioactinium preparation showed that the radiation could not be ascribed to some actinium $X$ which had not been separated. In addition it is seen that the soft type $\mu=25$ is quite distinct from the corresponding radiation from actinium B, viz. $\mu=31$. It is of interest to observe that the hard type of radiation from radioactinium appears to be slightly more penetrating than that emitted from actinium $\mathrm{D}$.

\section{Summary.}

For convenience, the types of $\gamma$ rays emitted from all the products so far examined are included in the following table. In order to complete the series it will be necessary to examine the types of $\gamma$ rays emitted by uranium X. It is intended to continue the experiments in this direction. 
the $\gamma$ Rays of the Thorium and Actinium Products. 943

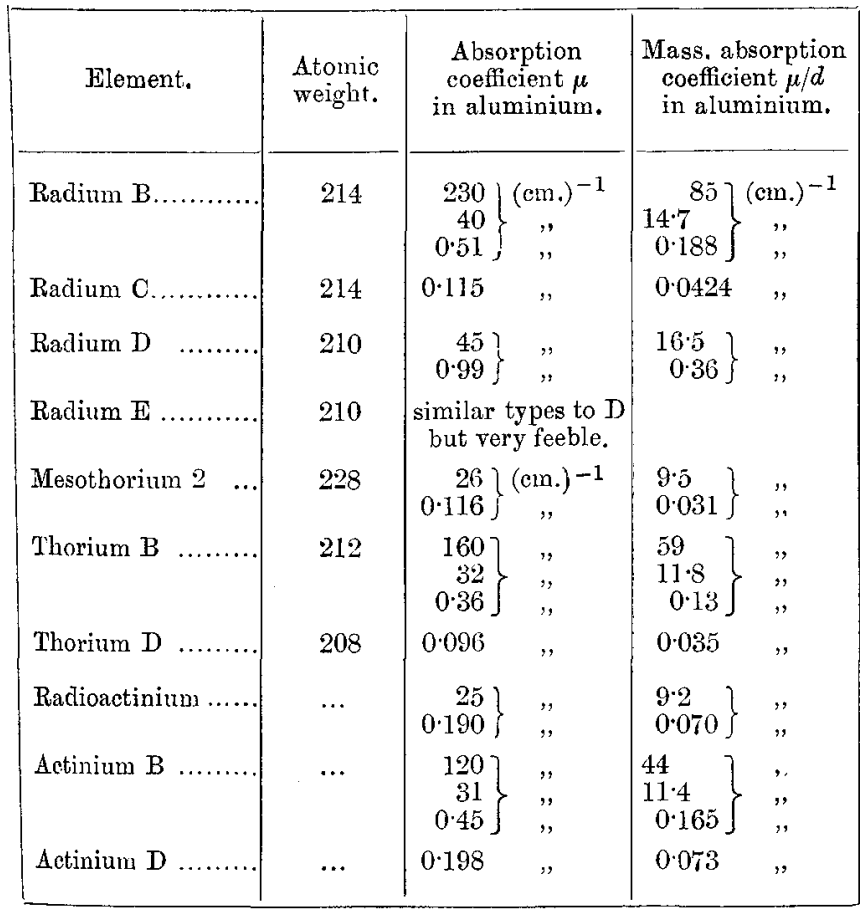

It will be seen that the $y$ rays from radioactive products can be conveniently divided into four types:-

(1) The soft radiations from the $B$ products which vary from $\mu=120$ to $\mu=230$.

(2) A more penetrating type varying from $\mu=26$ to $\mu=45$, probably corresponding to characteristic radiations of the " $\mathrm{L}$ " series.

(3) A penetrating type from the $B$ products varying from $\mu=\cdot 36$ to $\mu=\cdot 51$.

(4) A very penetrating type varying from $\mu=\cdot 115$ to $\mu=\cdot 198$, probably corresponding to characteristic radiations of the " $\mathrm{K}$ " series.

Types (1) and (2) are much less penetrating than the $X$ rays from an average tube, although the work of Bragg * and Moseley and Darwin $\dagger$ has clearly shown that types of radiation similar in penetrating power to (2) are present in $\mathrm{X}$ rays generated with a platinum anticathode. Using a hard bulb and a consequent very high voltage

* Bragg, Proc. Roy. Soc. A. 1xxxviii. p. 428 (1913).

$\dagger$ Moseley \& Darwin, Phil. Mag. xxri. p. 210 (1913). 


\section{Prof. Rutherford and Mr. Richardson : Analysis of}

$(100,000$ volts), S. J. Allen* showed that $X$ rays could be produced of penetrating power about corresponding to type (3). Type (4) is more penetrating than any $X$ rays produced or likely to be produced in X-ray tubes.

Thorium $\mathrm{D}$ emits the most penetrating type of $\gamma$ rays known, while radium $\mathrm{C}$ and mesothorium 2 come next with radiations of nearly equal penetrating power. Actinium products, as bas long been known, emit less penetrating types of radiation than radium or thorium products. The penetrating radiation from radium $D$ has no apparent analogy with that emitted by any other product.

\section{General Considerations.}

In the above table we have included the types of primary $\gamma$ rays emitted by radioactive substances. In every case the emission of the $\gamma$ rays observed is accompanied by a wellmarked primary $\beta$ radiation. As we have already pointed out in our experiments on radium $D$ and radium $\mathrm{E} f$, there does not appear to be any obvious connexion between the relative intensity of the $\beta$ and $\gamma$ rays. For example, consider the case of radium $\mathrm{D}$ and radium $\mathrm{E}$. On the one hand, radium $D$ emits a comparatively feeble $\beta$ radiation, shown by Hahn $\ddagger$ to consist of two groups of low velocity but a well-marked $\gamma$ radiation ; and on the other, radium $E$ emits an intense $\beta$ radiation comprising particles projected with nearly the velocity of light, but gives a $\gamma$ radiation exceediugly feeble in quantity compared with that from radium D.

The experiments of Hahn, v. Baeyer and Meitner have shown that practically all the $\beta$-ray products emit a number of distinct groups of $\beta$ rays of definite speed. The only exception to this is radium $E$ which gives a continuous spectrum of $\beta$ rays in which no evidence of groups has yet been observed. It should he mentioned also that no evidence of groups has so far been observed in the $\beta$ rays of uranium $\mathrm{X}$, but more experiments are required on this point. It may prove significant that radium $\mathbf{E}$, which shows no sign of definite groups of $\beta$ rays, should be the only $\beta$-ray product which emits $\gamma$ rays exceedingly feeble in intensity.

In addition to these primary $\gamma$ rays of marked intensity, Mr. Chadwick and Dr. Russell $\S$ have recently drawn

* S. J. Allen \& E. J. Lorentz, Phys. Rev. i. ser. 2, p. 35 (1913).

† Rutherford \& Richardson, Phil. Mag. xxvi. p. 324 (1913).

† Hahn, Baeyer \& Meitner, Phys. Zeit. xii. p. 378 (1911).

$\$$ Chadwick \& Russell, Proc. Roy. Soc. A. lxxxviii. p. 217 (1913). 
attention to the fact that substances which emit $\alpha$ rays also emit a $\gamma$ radiation of feeble intensity. This has been shown to be the case for the $\alpha$-ray substances ionium, radiothorium, and polonium.

They have also examined the $\gamma$ radiation from radium itself, which is also known to emit a weak $\beta$ radiation. With the exception possibly of radium, this $\gamma$ radiation observed from $a$-ray products has probably an entirely different origin from the intense primary $\gamma$ radiation from the $\beta$-ray products. It would appear to be excited in the radioactive atoms by the escape of $\alpha$ particles. In their experiments on the $a$-ray product ionium, Chadwick and Russell have drawn attention to the fact that the softer types of radiation predominate. This is the exact opposite of the primary $\gamma$-ray products, where the penetrating typos of radiation are relatively far more intense.

It is of interest to compare the types of primary $\gamma$ rays emitted by different radioactive products. In the first place, it is clear from the table that each of the products radium $\mathrm{B}$, thorium $\mathrm{B}$, and probably actinium $\mathrm{B}$, which occupy the same relative position in the radioactive series and have very similar if not identical chemical properties, emit three distinct types of $\gamma$ radiation which appear to be closely analogous in relative penetrating power. Similar results appear to hold for radium $C$, thorium $D$, and actinium $D$, each of which emits only one penetrating type of $\gamma$ radiation. Neither of the two products radium $D$ and radium $\mathrm{E}$ corresponds in radioactive or chemical properties with any member of the thorium or actinium series and alse shows no close analogy in their types of radiation.

In a previous paper * one of us has suggested that the types of $\gamma$ rays emitted by radioactive substances should correspond to one or more of the types of characteristic radiation excited in the atom by the escape of $\beta$ particles. For example, the single type of $\gamma$ radiation from radium $C$ and thorium $\mathrm{D}$ has about the penetrating power to be expected for a radiation of the " $K$ " series found by Barkla $†$.

It will be observed from the table tbat all the $B$ products emit a soft type of radiation which is on an average much less penetrating than ordinary $X$ rays. From a comparison of the results given by Chapman $\ddagger$ it would appear that the radiations from radium $B, \mu=40$, from thorium $B, \mu=32$,

* Rutherford, Phil. Mag. xxiv. p. 453 (1912).

† Barkla, Phil. Mag. xxii. p. 396 (1911).

† Chapman, Proc. Roy. Soc. ser. A. Ixxxvi. p. 439 (1912). 
from actinium $B, \mu=31$, and from mesothorium $2, \mu=26$, belong to the " $\mathrm{L}$ " series of Barkla. This type of radiation seems very persistent in all except the three products radium $C$, thorium $D$, and actinium $D$. It should be pointed out, however, that there appears to be no very close connexion between the penetrating power of the radiation and the atomic weight. For example, radium $\mathrm{B}$ of atomic weight 214 gives a radiation for which $\mu=40$, whilst thorium $\mathrm{B}$ of still lower atomic weight 212 gives a more penetrating radiation, $\mu=32$. This peculiarity holds not only for the soft radiations but also for the hard types emitted by the $B$ products. If the softer types of radiation do belong to the "L" series, it would appear that the general rule connecting penetrating power and atomic weight may hold approximately over wide ranges but not necessarily for products whose atomic weights differ only slightly from one another. It is difficult to offer any explanation why the $B$ products should give three types and the successive products only one type. It should be pointed out, however, that the $\beta$ rays from the $B$ products are on the average much less penetrating than the $\beta$ rays from the following products, and have consequently a much better chance of exciting the softer types of $\gamma$ radiation, that is, the radiations of longer wave-length. Also it should be noted that the expulsion of a long range a particle either accompanies or precedes immediately the penetrating $\gamma$ radiation from these products.

During the present year, Russell*, Fajans $†$, and Soddy $\ddagger$ have independently discussed the question of the chemical properties of the numerous radioactive products, and have shown that the sequence of chemical properties in a radioactive series follows a simple rule when the types of emitted radiation are taken into account. According to some of these views, the B products are to be regarded as chemically identical and inseparable from one another, although they may differ by about two units in their atomic weights. If we take the view that the atom consists of a positively charged nucleus of small dimensions surrounded by rings of electrons which can be set in vibration, it would seem probable that an identity of chemical nature would involve an identity in the electronic distribution and of the magnitude of the charge on the nucleus. If the $\gamma$ rays set up are due to the vibration of the electronic systems, it would be anticipated that the types of $\gamma$ rays emitted would be identical for such products. While, as we have previously

* Russell, Chem. News, cvii. p. 49 (1913).

† Fajans, Phys. Zeit. iv. p. 136 (1913).

† Soddy, Chem. News, cviii. p. 168 (1913). 
pointed out, there is an undoubtedly close analogy between the $\mathrm{B}$ products, not only in the types of radiation but also in the relative penetrating power, the differences in their penetrating power are sufficiently marked to indicate a real difference in the wave-length of the radiation emitted and one which cannot be attributed to experimental error.

It is of interest to examine whether a comparison of the types and penetrating power of the radiations from the thorium and actinium products gives any indication as to the atomic weight of the latter. It has already been mentioned that the " $\mathrm{L}$ " type of radiation seems to be predominant for most of the products, and for this radiation there is a close agreement between the penetrating powers of the radiations emitted by analogous products. For example, actinium $\mathrm{B}$ emits a radiation for which $\mu=31$, and a corresponding radiation $\mu=32$ is given out by thorium $\mathrm{B}$. The radiation $\mu=25$ from radioactinium also resembles closely the radiation from mesothorium 2, $\mu=26$. Considering the very close analogy in chemical and radioactive properties of the thorium and actinium series, it is reasonable to suppose that those bodies which emit similar types of radiation of nearly equal penetrating power have nearly the same atomic weight. For example, by considering the number of $\alpha$-ray products it can be estimated that thorium $B$ has an atomic weight 212. We should expect actinium $B$ to have an atomic weight nearly the same. In the same way we should expect radioactinium and mesothorium 2 to have nearly equal atomic weights. Calculating backwards by a consideration of the number of a-ray products, it can be deduced that the atomic weight of actinium should be (1) 228 , from comparison of the B products ; (2) 228 from comparison of radioactinium with mesothorium 2 .

It is quite probable from other analogies, that the actual atomic weight might be two units greater or less than the above value. In the one case, the atomic weight 230 would indicate that actinium was derived from uranium after the expulsion of two a particles, and the other that it arose from ionium. On this point of view radium itself does not seem admissible as a possible origin of actinium, and this is supported by the recent experiments of Soddy*. The deduction that actinium is derived from uranium seems the more probable, and several suggestions of this possibility have already been made $t$.

* Soddy, Nature, xci. p. 634 (1913).

+ Boltwood, Amer. Journ. Sci. xxv. p. 269 (1908). Hahn \& Meitner, Phys. Zeit. xvi. p. 752 (1913). Antonoff, Phil. Mag. xxii. p. 419 (1911). 


\section{Messrs. Marsden and Wood on the Determination of}

The other more penetrating types of radiation from the actinium and thorium products do not appear to be directly comparable. For example, the hard radiations from thorium $\mathrm{D}$ and actinium $\mathrm{D}$ show wide differences in penetrating power.

When the types of $\gamma$ radiation emitted not only by all $\beta$-ray products but also by all $\alpha$-ray products are known, very valuable data will have been obtained for throwing light not only on the modes of vibration of the radioactive elements but also on their atomic constitution.

University of Manchester, October, 1913.

LXXXIII. A Method for the Determination of the Molecular Weights of the Radioactive Emanations with Application to Actinium Emanation. By E. MARSDEN, M.Sc., and A. B. WOOD, M.Sc., University of Manchester *

$\mathbf{I}^{\mathrm{N}}$ all the methods previously employed to determine the molecular weights of the emanations from their rates of diffusion or effusion $\dagger$, the results have been dependent on a comparison of the corresponding rate for some other gas. Further, the measurements in most cases are undoubtedly affected by the fact that it is impossible to deal in this way with the emanations except when mixed in extremely small proportion with other gases. In the method to be described both these objections are avoided by working at such low pressures that the molecules have a mean free path large in comparison with the size of the containing vessel, and by using definite kinetic theory data not involving comparison with other gases.

Suppose we have two vessels I. and II. of volumes $V_{1}$ and $V_{2}$ separated by a hole of area $A$ and containing $N_{1}$ and $N_{2}$ molecules per c.c. respectively. Then if $\Omega$ is the mean molecular velocity, it can be calculated from the kinetic theory that the number of molecules from I. passing through the 'opening will be $\frac{1}{4} \mathrm{~N}_{1} \Omega \mathrm{A} \ddagger$, and the number returning from II. will be $\frac{1}{4} \mathrm{~N}_{2} \Omega \mathrm{A}$. Consequently, on the whole $\frac{1}{4} \Omega A\left(N_{1}-N_{2}\right)$ molecules will cross from I. to II. per second.

Suppose that molecules of actinium emanation are supplied at a constant rate in $I$. and allowed to pass into II. Then a

* Communicated by Prof. F. Rutherford, F.R.S.

+ E. Rutherford, "Radioactive Substances," p. 379 et seq.

† M. Knudsen, Ann. d. Physik, xxviii. p. 999 (1909). 


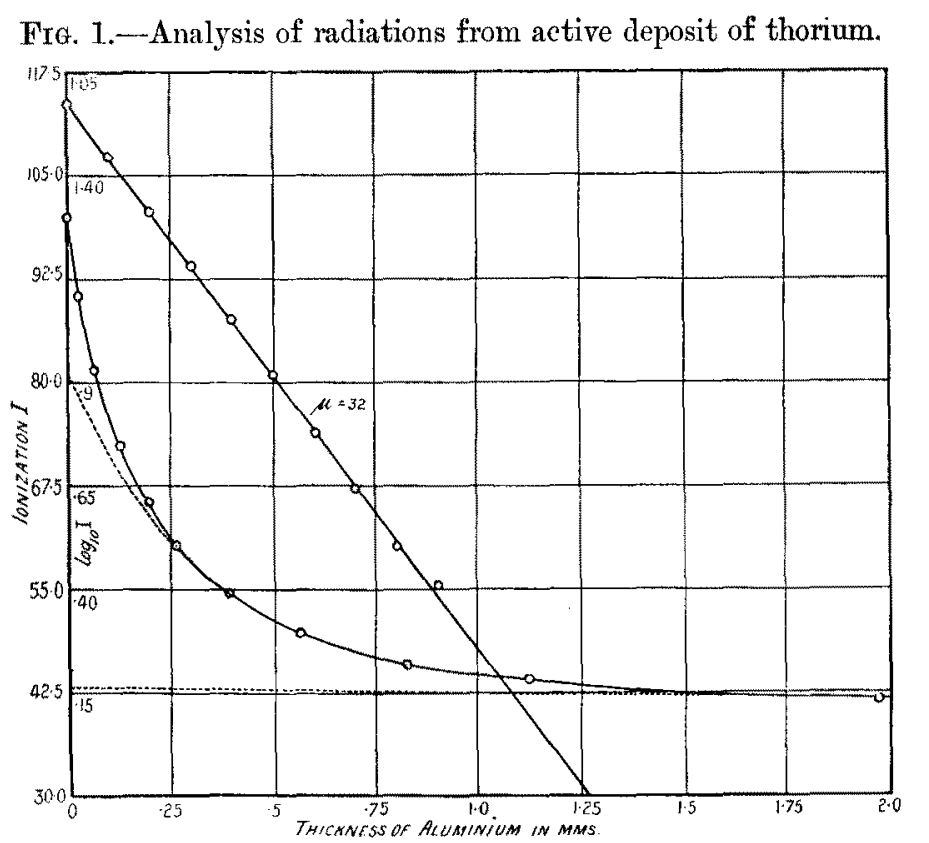

FIt. 2.-Analysis of $\gamma$ rays from active deposit of thoriun.

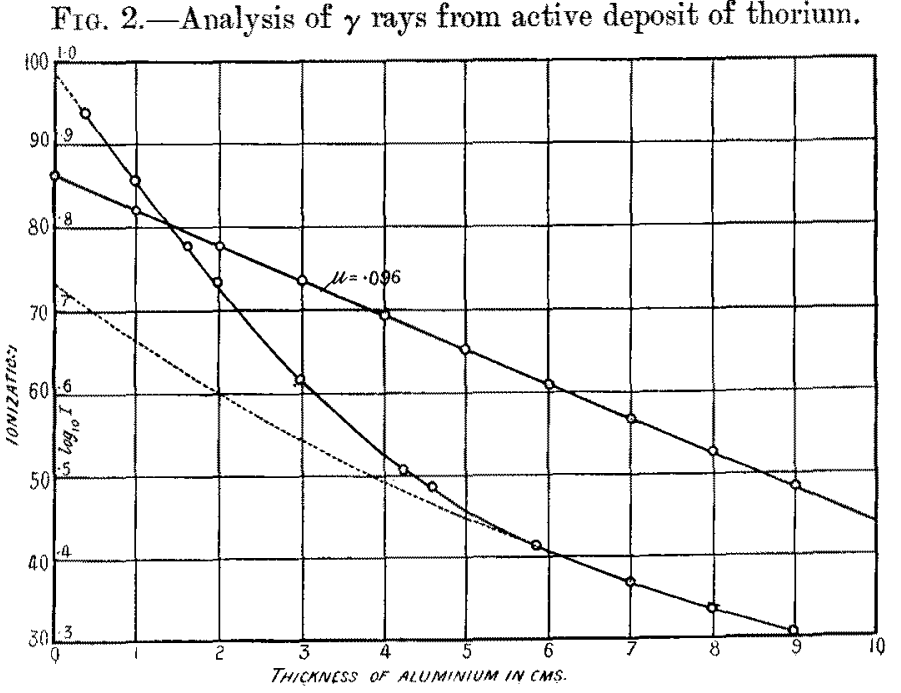

Fra. 3.-Analysis of $\gamma$ radiation from mesothorium 2 .

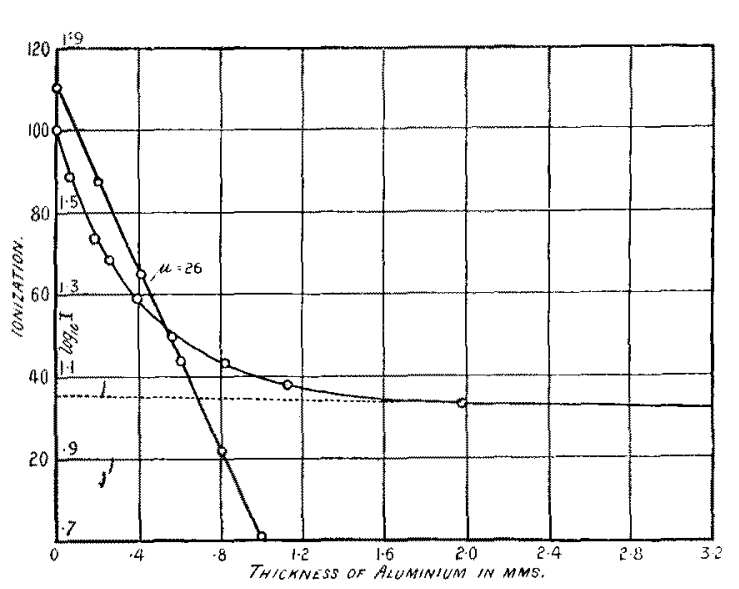

Fra. 4.-Penetrating $\gamma$ radiation from mesothoriun 2

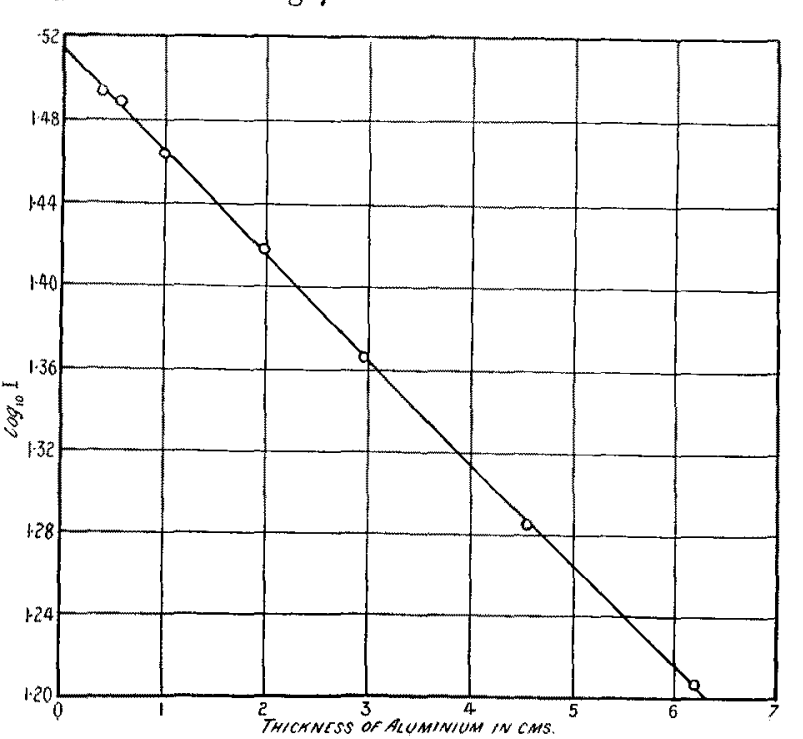

F'Ta. 5.-Analysis of $\gamma$ radiations from active deposit of actinium.

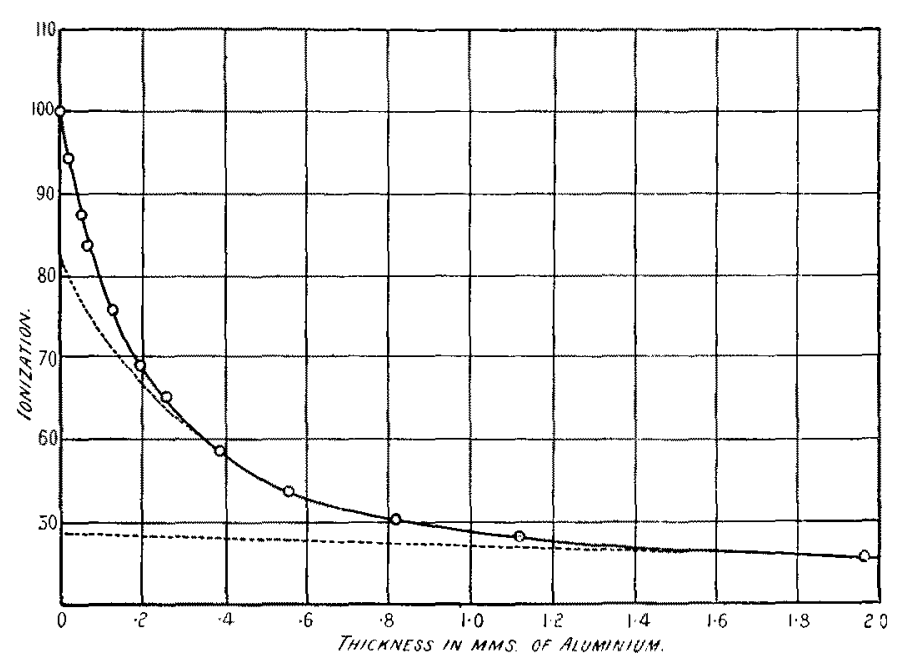

FIa. 6.-Analysis of $\gamma$ radiation from active deposit of actinium.

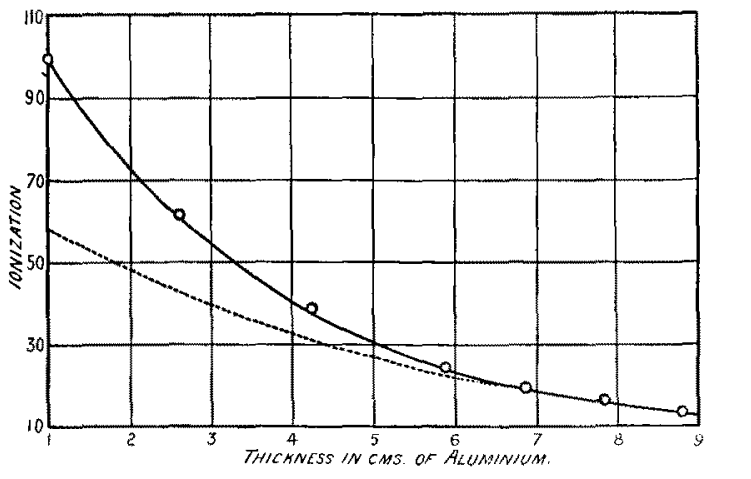

Frd. 7,-Analysis of $\gamma$ radiation from radioactinium.

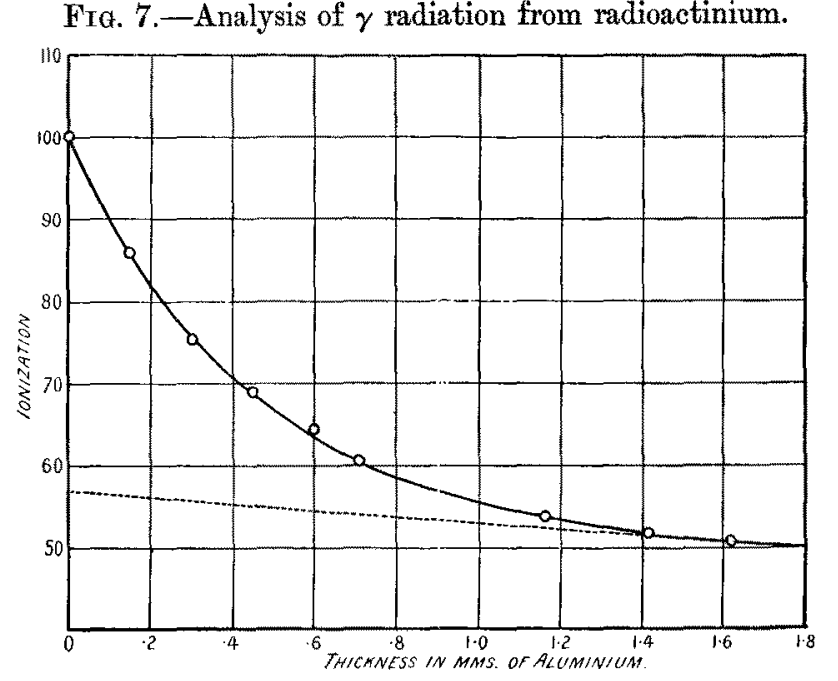

Fra. 8. - Penetrating $\gamma$ radiation from radioactiniun.

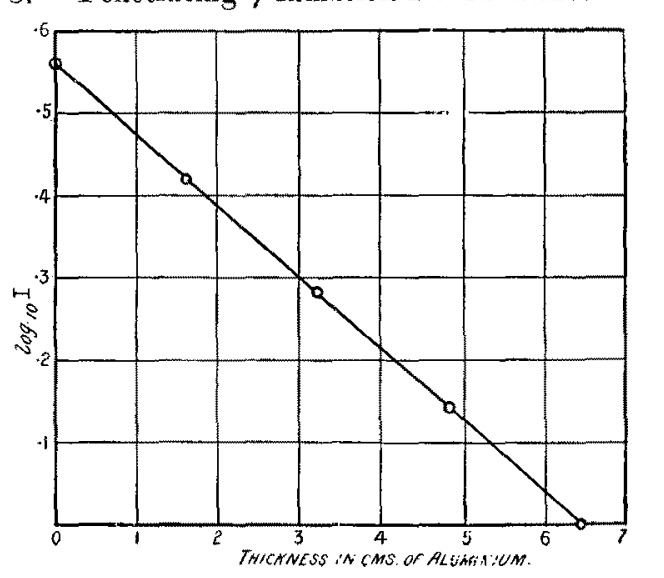

